\title{
Measurement of the wall slip behaviour of a solid granular soap in ram extrusion
}

\author{
M. P. Bryan, S. L. Rough, D. I. Wilson \\ Department of Chemical Engineering and Biotechnology, University of Cambridge, Philippa \\ Fawcett Drive, Cambridge, CB3 OAS, UK
}

\begin{abstract}
The wall slip behaviour of a solid granular soap was investigated in the context of ram extrusion, with particular focus on determining the sensitivity of the wall shear stress to the pressure within the soap, as well as the slip velocity. Two novel slip measurement devices were used to infer the shear stress: a two stage extrusion die with inbuilt pressure gradient measurement; and a combined compression-translation assembly to measure the frictional force between the soap and the wall. Both devices provided differing measurements of the pressure sensitivity, and gave shear stress estimates in agreement with a Benbow and Bridgwater (1993) analysis of the extrusion behaviour, which cannot gauge pressure dependence.

The influence of the wall material on the slip and extrusion behaviour was also investigated, using three geometrically identical extruders constructed from polycarbonate, stainless steel and tungsten carbide. There was found to be a non-negligible relationship between wall material, wall surface roughness, and the Benbow-Bridgwater extrusion parameters, in which the wall shear stress was greatest against the smoothest, cemented tungsten carbide wall in contrast to a rougher stainless steel and rougher-still polycarbonate wall.
\end{abstract}

Keywords: extrusion, wall slip, soft solids

*Corresponding author, slr1002@cam.ac.uk, +44(0)1223 334772 


\section{Introduction}

The extrusion of dense solid-liquid suspensions is used as a net shape forming method for a wide range of products, from foodstuffs to machining tools (Wilson and Rough, 2006). A common feature of the flow of these materials is wall slip,

5 and in particular apparent slip as described by Barnes (1995). True slip, in which the fluid molecules slide directly along the wall, is not typical of suspensions but has been noted in polymer melts (Ansari et al., 2012).

Wall slip is often reported in studies of dense suspensions and related materials, e.g. Martin and Wilson (2005), Kalyon (2005) and Mitsoulis and Hatzikiriakos (2009). One mechanism for apparent slip in suspensions is the spontaneous reduction of the effective solids volume fraction adjacent to the wall, described in detail by Kalyon (2005). Owing to the strong relationship between the solids volume fraction and viscosity (e.g. Krieger and Dougherty 1959), this layer of reduced viscosity acts as a lubricant between the stationary wall and the bulk flow giving the appearance of slip macroscopically.

Most measurements of slip in the literature are motivated by a need to quantify and subsequently remove it from rheological measurements. Mooney (1931), Jastrzebski (1967) and Yoshimura and Prud'Homme (1988), among others, all describe experimental procedures for correction of capillary, Couette and parallel plate rheometry data from wall slip effects. As wall slip effectively enhances the flow of material within a channel, its occurrence manifests as a larger apparent shear rate than the true value. The degree of error does however scale with the size of the rheometer, and extrapolation to the no slip case is often made by testing a material using different gap sizes or channel diameters to obtain the true apparent viscosity curve. The above procedures are not always successful or appropriate for slip in dense suspensions, however, as noted by Martin and Wilson (2005), and the modelling of such flows remains the subject of ongoing research.

Navier (1823) was the first to propose a slip model based on tangential motion of fluid molecules in contact with a solid surface, relating the velocity 
of slip $V_{\text {slip }}$ to the velocity gradient normal to the wall, as in equation 1 for a cylindrical coordinate system ( $r$ is the radial coordinate, $V$ is the fluid velocity). The constant $b$ has units of length and is referred to as the slip length; this can be interpreted geometrically as the distance into the wall at which the velocity profile would become zero.

$$
b \frac{\mathrm{d} V}{\mathrm{~d} r}=V_{\text {slip }}
$$

The Navier model is formulated for true slip as defined above, but it is also applicable to apparent slip systems where the velocity gradient of the bulk flow near the wall is used, rather than that of the low viscosity depleted layer which itself has a zero slip velocity. The Navier model is formulated for fluids of constant viscosity, though it can be extended by considering the relationship of the shear stress at the wall $\left(\tau_{\mathrm{W}}\right)$ to the shear rate, as in equation 2 , where $\eta$ is the apparent viscosity.

$$
\tau_{\mathrm{W}}=\eta \frac{\mathrm{d} V}{\mathrm{~d} r}=\frac{\eta}{b} V_{\text {slip }}=\beta V_{\text {slip }}
$$

The parameter $\beta$ is the slip coefficient and for a non-Newtonian fluid is a function of both the material and the slip behaviour. The relationship between $\tau_{\mathrm{W}}$ and $V_{\text {slip }}$ is sometimes found to be non-linear (Hatzikiriakos and Mitsoulis, 2009; Wang et al., 2010), and the Navier model can be extended as shown in equation 3 where $n$ is the power-law exponent for the slip behaviour. This is justified by the likely non-Newtonian rheology of the depleted layer, particularly if the liquid binder itself is non-Newtonian.

$$
\tau_{\mathrm{W}}=\beta V_{\mathrm{slip}}^{n}
$$

The Navier slip condition can be viewed in contrast to the basic model of Coulombic solid-solid friction, in which the tangential stress is independent of sliding velocity but directly proportional to the normal stress. Benbow and Bridgwater (1987) proposed two hybrid slip functions for paste flows based on the Navier model, incorporating pressure dependence in place of normal stress, given as equations 4 and 5 , where $b_{1}$ is a constant, $\mu$ is a friction coefficient and $P$ 
is the pressure at the wall. These models were motivated by experimental data from extrusion of alumina pastes, though pressure-dependent slip has also been observed in molten polymer systems (Hatzikiriakos and Dealy, 1992; Stewart, 1993).

$$
\begin{aligned}
& \tau_{\mathrm{W}}=\tau_{0}+\mu P+\beta V_{\mathrm{slip}}^{n} \\
& \tau_{\mathrm{W}}=\tau_{0}+b_{1} P V_{\mathrm{slip}}^{n}
\end{aligned}
$$

Here, $\tau_{0}$ is the stress required to initiate slip at the wall, sometimes referred to as a slip yield stress. It is analogous to the shear force required to initiate sliding at a solid-solid boundary represented by the static friction coefficient. In an apparent slip system a slip yield stress is logical as the lubricating layer forms primarily due to a shear rate gradient at the wall (Leighton and Acrivos, 1987). Starting from rest, the densely packed arrangement of particles close to the wall must be broken down before slip can initiate.

This work presents several measurements of the wall slip of a solid granular soap in the context of extrusion. While soap is not a solid-liquid suspension in the conventional sense, it does contain some moisture and acts as a lubricant under certain circumstances, being used as a base for lubricating greases. It is 40 an interesting candidate for a material which could display either solid-like slip (normal stress-dependent, velocity-independent) or liquid-like slip as described above (normal stress-independent, velocity-dependent). Extrusion of soap materials has been studied previously, for example by Amarasinghe and Wilson (1998), Domanti and Bridgwater (2000), Kalyon et al. (2004) and Barnes et al.

45 (2006), where soaps were found to be reproducible and reliable extrusion materials with behaviour conforming to the Benbow and Bridgwater (1993) model for extrusion. It is important to distinguish between solid soap as studied here, consisting of pure stearates with minimal water content, from bar soaps or soaps containing fragrances or softeners (often oil-based), such as those studied by Ka-

50 lyon et al. (2004) and Barnes et al. (2006), which have additional liquid content and as such flow more readily. 
In particular, the present work seeks to determine whether the wall slip behaviour of soap is pressure dependent, as in equation 4 or 5 . Also tested is the effect of the wall itself on the slip behaviour. The wall material is of consequence to solid-solid friction measurements, where friction coefficients are always defined for a pair of materials, but has to the best of our knowledge not yet been studied in the context of dense suspensions or paste extrusion.

\section{Materials and methods}

A commercial solid granular soap was sourced to act as the test material (Dri-

60 Pak Ltd, UK), which the manufacturer indicated was produced from a blend of sunflower and coconut oils with no additives, and as such is likely to contain only pure stearates, which are a solid lubricant. The soap consisted of flat, plate-like granules of typical size $5 \mathrm{~mm}$ with a translucent cream colour. The moisture content of the soap was determined by vacuum drying to be around $7.5 \mathrm{wt} \%$.

65 Further investigations into the extrusion behaviour of the soap can be found in Bryan et al. (2017). Differential scanning calorimetry of the material indicated a broad melting band beginning at approximately $45^{\circ} \mathrm{C}$ which would manifest in a gradual softening of the soap material. All experiments were conducted in a temperature- and humidity-controlled laboratory at $23^{\circ} \mathrm{C}$ and $50 \%$ R.H., though the extrusion tooling itself was not temperature controlled.

\subsection{Standard extrusion protocol}

The extrusion behaviour of the soap was classified using the Benbow and Bridgwater (1993) approach, which relates the pressure required to extrude the material to aspects of the extruder geometry, a material yield stress $\left(\sigma_{\mathrm{Y}}\right)$ and a wall shear stress in the extrusion die $\left(\tau_{\mathrm{W}}\right)$. In the current context the wall shear stress is of most interest as it can be interpreted in the context of the slip models presented previously, in particular equation 4 with zero pressure dependence ( $\mu$ set to zero).

The ram extruder used was of the concentric cylinder, square-entry type so (shown in figure 1) with barrel diameter $25 \mathrm{~mm}\left(D_{0}\right)$ and die diameter $3 \mathrm{~mm}$ 
$(D)$. Dies of length $(L) 16,22,28,40,52$, and $58 \mathrm{~mm}$ were used. The maximum extrusion pressure attainable with the device was $120 \mathrm{MPa}$ and the maximum ram velocity $\left(V_{\text {ram }}\right)$ was $10 \mathrm{~mm} / \mathrm{s}$. The extrudate is assumed to undergo complete slip against the wall of the die at a velocity $V_{\mathrm{ex}}$, the extrudate ve-

85 locity, estimated by conservation of volumetric flow between the barrel and die $\left(V_{\mathrm{ex}} D^{2}=V_{\mathrm{ram}} D_{0}^{2}\right)$ assuming incompressibility of the material, which is standard practice in extrusion studies of this type. Details of the operation of the extruder can be found in Bryan et al. (2015).

Three sets of extrusion tooling (barrels and dies) were fabricated from stainless steel (SS), polycarbonate (PC) and cemented tungsten carbide (WC) in order to ascertain the effect of wall material on the slip behaviour (to be gauged through variation in $\tau_{\mathrm{W}}$ ). The surface finishes of each set could not be made equal owing to constraints on the manufacturing, although all cylindrical surfaces were reamed to achieve even finishes. To account for the differences in each surface, surface roughness measurements were taken using a stylus profilometer (Form Talysurf 120, Taylor Hobson Ltd, UK). A summary of $R_{\mathrm{a}}$ values (arithmetic average of absolute deviation) for the barrel walls is given in table 1 . The roughnesses of the dies could not be tested owing to the narrow diameters of the channels, but are assumed to be similar.

The surface roughness varies noticeably, with $\mathrm{PC}$ having the roughest surface (likely due to faster machining). The difference of nearly two orders of magnitude means that interpretation of the results from each extruder set must take into account both the wall material and the roughness, and it is not possible to decouple the effects. While this is not ideal, constraints on manufacturing new tools meant the above sets were used.

\subsection{Two-stage extrusion die}

While the Benbow-Bridgwater approach gives an estimate of $\tau_{\mathrm{W}}$, the wall shear stress in the die, it does not provide insight on the pressure in the flowing material and as such gives an incomplete description of the state of stress at the wall. This has the potential to obscure more complex slip behaviour than that 
initially assumed by Benbow and Bridgwater.

The two-stage extrusion die consists of a device to measure the pressure gradient within a flowing extrudate, from which the slip behaviour can be inferred independently of the bulk deformation behaviour, while also allowing the pressure that the slipping material is experiencing to be changed.

The device, shown in figure 2, is a stainless steel 'primary' cylindrical extrusion die of diameter $11 \mathrm{~mm}\left(D_{\mathrm{p}}\right)$ and length $110 \mathrm{~mm}\left(L_{\mathrm{p}}\right)$, which is attached to a $25 \mathrm{~mm}$ diameter extrusion barrel. Three radially-facing pressure transducer ports are located along the die wall, spaced $25 \mathrm{~mm}$ apart. Kulite XTM-190(M) transducers (Kulite Semiconductor Products, Inc., USA) were used to measure the pressure gradient (effective operating range 0-35 MPa). It is possible to attach a small, secondary die at the exit of the main channel, creating in effect a second extruder. A range of 'secondary' dies was constructed from stainless steel with diameters of 3,4 and $6 \mathrm{~mm}$ and lengths ranging from 5 to $35 \mathrm{~mm}$.

By adjusting the ram velocity in the barrel, the slip velocity in the primary die can be modified. Meanwhile, the pressure in the primary die can be adjusted by applying a larger $L / D$ secondary die, which increases the resistance to flow through the system.

The flow in the primary die is predominantly plug-flow due to the material yield stress with little, if any, bulk deformation. Unlike in the barrel, where the billet becomes shorter with ram displacement, the length of the material flowing in the primary die is constant. The result is that the three transducers should measure a constant pressure gradient throughout the extrusion. The wall shear stress $\tau_{\mathrm{W}}$ is calculated via a simple force balance on the confined material, equation 7 :

$$
\begin{gathered}
\underbrace{\pi D_{\mathrm{p}} \tau_{\mathrm{W}} \mathrm{d} z}_{\text {Force from wall }}=\underbrace{\pi \frac{D_{\mathrm{p}}^{2}}{4} \mathrm{~d} P}_{\text {Force on cross-section }} \\
\tau_{\mathrm{W}}=\frac{D_{\mathrm{p}}}{4} \frac{\mathrm{d} P}{\mathrm{~d} z}
\end{gathered}
$$

where $z$ is the axial coordinate and the $P$ is the pressure. A necessary assump- 
tion is that the measured radial pressure is equivalent to the axial stress on the cross-section, implying that the stress state is locally isotropic. While it was not possible to measure this axial stress in the primary die directly to confirm this assumption, measurements were made of the axial and radial pressure just upstream of the primary die entrance, in the main barrel. The pressures measured by two transducers, one embedded in the die face (axial orientation, 10 $\mathrm{mm}$ radius from the centre) and the other in the barrel wall (radial orientation, $12.5 \mathrm{~mm}$ above the die face) were found to be equivalent for the solid granular soap.

\subsection{Compressed slip device}

A further advance on the ability to decouple wall slip from flow behaviour as well as control the pressure in the slipping material is the compressed slip device (shown in figure 3). A cylinder of the test material is confined between two brass platens in a cylindrical channel, with the confinement pressure adjusted by clamping the platens closer together. The assembly is then translated along the channel while the force required to cause the motion is measured. This force, once corrected for friction between the platens and the wall, is directly linked to the material-wall shear stress.

The translation action and force measurements are carried out by an instrumented strain frame, allowing the translation speed (essentially the slip velocity) to be set from 0 to $10 \mathrm{~mm} / \mathrm{s}$. The cylindrical channel is the stainless steel extrusion barrel of diameter $25 \mathrm{~mm}$ described above. The compaction pressure in the billet was measured using a pressure transducer embedded axially in the bottom platen, slightly offset from the central connecting rod. To control leakage, each platen was machined to include a $1 \mathrm{~mm}$ Viton O-ring (DuPont Performance Elastomers LLC, USA) in contact with the wall.

The device allows confining stresses to be generated up to and including the $35 \mathrm{MPa}$ limit of the embedded pressure transducer. A similar device was used by Benbow and Bridgwater (1987) for measuring pressure-dependent slip in alumina pastes; their device used the action of a spring to compress the sample. 
the test, preventing transient slip effects from being observed.

The frictional force $F$ measured by the load cell was converted to a wall shear stress assuming $\tau_{\mathrm{W}}$ to be uniform across the billet surface, i.e. $\tau_{\mathrm{W}}=$ $F / \pi D_{0} L_{\mathrm{b}}$ where $L_{\mathrm{b}}$ is the billet height. For a granular material, however, $\tau_{\mathrm{W}}$ may not be uniform over the surface due to the distribution of radial stress from compression, and heterogeneity on the billet surface itself. This was taken into account by measuring wall slip in billets of different aspect ratio, with heights ranging from 13 to $73 \mathrm{~mm}$. The distribution of $\tau_{\mathrm{W}}$ should become more uniform in shorter billets, and hence taking a simple average over the contact area would be more valid.

The residual friction between the platens and the wall was measured by conducting a test with no material sample at each translation speed. The results were then subtracted from measurements made with samples loaded. The residual forces are typically 1-2 orders of magnitude smaller (at 10-20 N) than those when using solid soap in the device.

It is possible that the residual friction is affected by the confinement pressure. This was not possible to measure directly as the seals cannot be put under stress without a sample of material being loaded.

A standard experiment involved translating the assembly in both directions along the channel at the same speed, followed by an increase in velocity for a further cycle. This pattern generated a sequence of positive and negative slip forces which increased with time. Between each stage a period of recovery time was observed (typically 10 seconds) to allow any frictional heat to dissipate. The final stage was a repeat of the first velocity to gauge whether the material had suffered any hysteresis.

\section{Results and discussion}

\subsection{Benbow-Bridgwater characterisation with different wall materials}

The Benbow-Bridgwater characterisation of soap in each barrel and die set is shown in figure 4 . Since the barrels and dies are of identical geometry, all 
wall-specific effects would be characterised by changes to the parameters $\sigma_{\mathrm{Y}}$ and $\tau_{\mathrm{W}}$, and in particular the latter. The values of the parameters at each extrudate velocity, $V_{\mathrm{ex}}$, are derived from the slope and intercept of a graph of extrusion pressure against increasing die length (specifically $L / D$ ) at that $V_{\mathrm{ex}}$; $\tau_{\mathrm{W}}$ is calculated from the slope whereas $\sigma_{\mathrm{Y}}$ is derived from the intercept. The extrusion pressure data were found to be suitably linear to carry out such a calculation of $\sigma_{\mathrm{Y}}$ and $\tau_{\mathrm{W}}$ in each case.

Referring to the surface roughness of each extruder (table 1), the smooth tungsten carbide walls might be expected to decrease the resistance to wall slip as the solid soap would not need to deform so severely around surface features. However, the opposite effect is seen, with the measured wall shear stress $\left(\tau_{\mathrm{W}}\right)$ decreasing with increasing surface roughness. The associated trend in $\sigma_{\mathrm{Y}}$ is harder to attribute to changes in the wall material as it is intended as a property of the material rheology alone. In this instance it is likely that the trend is due to the fitting process used to derive $\tau_{\mathrm{W}}$ and $\sigma_{\mathrm{Y}}$, in which an increased slope on a plot of extrusion pressure against $L / D$ (giving $\tau_{\mathrm{W}}$ ) will lead to a lower intercept $\left(\sigma_{\mathrm{Y}}\right)$ and vice versa.

The coupled variation in wall material and surface roughness makes isolating the cause of this trend difficult. A thermal mechanism to explain the data is that frictional heating would be expected to increase against rougher surfaces, while the rate of heat sinking by the wall would increase with larger thermal diffusivity. Heating of the soap against each wall may influence localised melting and lubrication and hence the wall slip. Referring to the roughness and thermal diffusivity values in table 1 , both properties of each wall tested agree with the trends in the observed data.

Wall heating effects are not, however, able to account for their differences in all aspects. Estimates of heat sink capacity (not reported) indicated that a $20 \mathrm{~K}$ rise in local temperature required for the soap to reach the softening threshold (as inferred from calorimetry data) was unlikely to occur in the metal extruders. Furthermore, the linearity of the extrusion pressure versus $L / D$ plots, used in 20 the determination of the Benbow-Bridgwater parameters $\sigma_{\mathrm{Y}}$ and $\tau_{\mathrm{W}}$, indicated 
little effect of contact time at the wall. If viscous heating was significant, the soap layer at the wall would be expected to be heated more, and therefore soften more, with longer dies.

Systematically decoupling the effect of surface roughness from the wall material was beyond the scope of the current work, as the surface finishes of the tools used were the standard available at the time of machining. The results serve as an indication of the potential effect of extruder construction on wall slip and indeed extrusion behaviour as a whole. It would be useful to conduct tests in which the roughness can be more carefully controlled, allowing effects such as the balance between frictional heating and local heat sinking to be investigated.

\subsection{Two-stage extrusion die}

Extrusion profiles for soap in the two-stage extrusion die are shown in figure 5. The velocities used represent both limits of ram (and hence slip) velocity.

The increased noise in the pressure readings at the lower extrusion velocity is likely due to poor compaction of the soap in the primary die at lower extrusion pressure. Several tests were also conducted without a secondary die (data not shown), hence at very low extrusion pressures, in which the extrudate was found to be very brittle and fractured easily. These features would register as fluctuations in the measured pressure as they passed each transducer embedded in the primary die. Such noise in extrusion pressure data was investigated in detail by Amarasinghe and Wilson (1998).

For experiments using secondary dies, the data can be processed to provide an instantaneous wall shear stress by estimating a linear pressure gradient from the three transducer readings. The instantaneous $\tau_{\mathrm{W}}$ does not change substantially throughout the extrusion, as shown for a single velocity in figure 6 . The fluctuations in $\tau_{\mathrm{W}}$ arise from noisy pressure transducer readings, but they do appear to be evenly distributed around a mean, implying that the soap-wall behaviour itself is effectively constant.

The figure also shows that there is no correlation between secondary $L / D$ and $\tau_{\mathrm{W}}$, indicating a slip mechanism which is only weakly pressure-dependent. 
The fact that the soap is mostly dry makes this a surprising result, as it might be expected to conform to a solid-solid friction which depends on normal stress. The magnitude of $\tau_{\mathrm{W}}$ is, however, consistent with the data derived from the Benbow-Bridgwater analysis of soap extrusion in figure 4 (viz. $\tau_{\mathrm{W}} \approx 0.15 \mathrm{MPa}$ ${ }_{255}$ at $V_{\mathrm{ex}}=30 \mathrm{~mm} / \mathrm{s}$ for $\left.\mathrm{SS}\right)$.

Extrusions using the two-stage die were conducted over the full range of possible ram velocities and using the four secondary dies indicated in figure 6 . The $\tau_{\mathrm{W}}$ data, derived from the primary die pressure gradients, are shown in figure 7. The lines fitted to the data in each plot assume slip behaviour which is solely a function of pressure or velocity, respectively. In all probability the behaviour is dependent on some combination of the two parameters, forming a three dimensional surface in both variables of the form suggested by equation 4. Fitting this equation to the whole data set provides values of: $\tau_{0}=0.1$ $\mathrm{MPa}, \mu=0 \mathrm{MPa} / \mathrm{MPa}, \beta=0.75 \mathrm{MPa} /(\mathrm{m} / \mathrm{s})^{n}$ and $n=0.75$. The value $\mu$ ${ }_{265}=0 \mathrm{MPa} / \mathrm{MPa}$ in this simultaneous fit indicates that there is no correlation of $\tau_{\mathrm{W}}$ with pressure, corroborated by the high degree of scatter in figure $7(\mathrm{a})$. Equation 5, which combines a multiple of pressure and velocity to model $\tau_{\mathrm{W}}$, did not provide a good fit to the data owing to its insistence on some degree of correlation with pressure.

The data do, however, display a reasonable correlation between $\tau_{\mathrm{W}}$ and $V_{\text {slip }}$, and agree in magnitude with the Benbow-Bridgwater analysis. A lack of pressure dependence is the typical assumption when analysing apparent, liquid layer-mediated slip in suspensions, although studies such as Tang and Kalyon (2008) have shown that pressure-dependent wall slip can lead to flow instabilities. With the solid soap tested here it is unlikely there is sufficient liquid to allow the liquid layer-mediated mechanism to occur, though the lubricating properties of the material may allow it to emulate the liquid-rich layer in these circumstances. 


\subsection{Compressed slip device}

8, using a confining pressure on the order of $5 \mathrm{MPa}$. Positive slip force corresponds to positive displacement in the channel (vertically downwards), and negative slip force corresponds to the return to the initial position. The data presented are corrected for residual friction between the rig and the wall as described previously.

The friction force recorded is a function of the slip velocity and shows agreement with the trend presented earlier. The first and last stages of the experiment were both conducted at $0.5 \mathrm{~mm} / \mathrm{s}$ and showed minimal difference in the slip behaviour over the course of the test, suggesting there were minimal changes to the billet itself (due to softening, say) which may have influenced the results. Also interesting to note are the slip force transients at the initiation of motion in each direction; these are indicative of a static to dynamic friction transition typical of solid-solid contact behaviour.

To calculate a wall shear stress from the raw force data, it is necessary to assume that the stress normal to the wall does not vary substantially with axial position in the billet. This condition is more likely to be true for short billets than long, as there is less surface over which to average the force. Results from tests with billets of different lengths (given as an aspect ratio $L_{\mathrm{b}} / D_{0}$ ) are shown in figure 9 .

300

Longer billets appear to slip with a lower wall shear stress, implying that the soap-wall friction force is not evenly distributed. Allowing for the degree of noise in the data, however, the calculated stress does tend towards being independent of the billet length as the aspect ratio is reduced. An $L_{\mathrm{b}} / D_{0}$ value of 0.52 was the smallest that could be practically used owing to the clearance required between the upper platen and the lower nut. An aspect ratio of 0.76 was chosen for further experiments due to more straightforward assembly of the device within the channel.

Figure 10 summarises some of the results from experiments with billets of length $19 \mathrm{~mm}\left(L_{\mathrm{b}} / D_{0}=0.76\right)$. The data are displayed on two plots separately 
three dimensional plot against both variables. Due to a gradual loss of confining pressure throughout each experiment, likely due to small amounts of leakage of material around the O-ring seals, it is necessary to categorise the data in figure 10(a) into bands of pressure $4 \mathrm{MPa}$ wide.

315 with similar magnitudes of $\tau_{\mathrm{W}}$, albeit with substantial scatter at larger confining pressures. The pressure dependence is subject to an even larger degree of uncertainty, though there is a consistent positive correlation between $\tau_{\mathrm{W}}$ and the confining pressure. This scatter implies there are other factors influencing the recorded slip force which are of a similar magnitude to the pressure dependence; these could arise from slight differences in the billet surface in each experiment, or in the rate of the aforementioned leakage of material from the device.

While the data are scattered, the number of $\tau_{\mathrm{W}}$ measurements allows some estimate of trends in the slip behaviour to be made. The power-law-like velocity dependence and the weak pressure dependence permits parametric fitting to a slip model such as equation 4 . This fitting yields the following values: $\tau_{0}=0$ MPa, $\mu=0.0046 \mathrm{MPa} / \mathrm{MPa}, \beta=2.61 \mathrm{MPa} /(\mathrm{m} / \mathrm{s})^{n}$ and $n=0.61$. As with the two-stage extrusion die, equation 5 was found not to fit the data well in comparison to equation 4 , and as such the parameters have not been reported.

The zero value of $\tau_{0}$, the slip yield stress, in particular is questionable as there is evidence of a static to dynamic friction transition in the raw data presented above. A better estimate of this parameter could be ascertained by conducting compressed slip device experiments gradually increasing the force applied to the billet, starting from rest and recording the start of translation, and subsequently reducing the force until cessation of movement. Unfortunately this was not possible due to limitations of the equipment, but would be an avenue for further work. 


\subsection{Comparison of methods}

Comparing results from all three methods of wall slip measurement must be

340

The Benbow-Bridgwater approach covers the widest range of velocities (from 0 to $250 \mathrm{~mm} / \mathrm{s}$ in the current configuration) but at an uncontrolled pressure, likely on the order of $10 \mathrm{MPa}$. In contrast, the two-stage extrusion die covers a $0-50 \mathrm{~mm} / \mathrm{s}$ range while the compressed slip device only covers $0-10 \mathrm{~mm} / \mathrm{s}$.

${ }_{345}$ The smallest extrusion velocity used in the Benbow-Bridgwater analysis was $10 \mathrm{~mm} / \mathrm{s}$, which precludes direct comparison with the compressed slip device except in the most qualitative sense.

Such a comparison is shown in figure 11. This uses a direct fit to the BenbowBridgwater data and the four parameter slip model (equation 4) evaluated at 10 slip device. As noted, at the lowest velocities the estimated $\tau_{\mathrm{W}}$ values are very sensitive to any potential slip yield stress $\left(\tau_{0}\right)$, particularly for the BenbowBridgwater estimate as there is only one datum defining the shape of the curve below $V_{\text {slip }}=10 \mathrm{~mm} / \mathrm{s}$.

355 Benbow-Bridgwater results agree. This is reassuring as they are based on similar principles, i.e. they both use an estimate of the pressure gradient in the flowing material in the die. The compressed slip device estimate of $\tau_{\mathrm{W}}$ is larger, but is the only method to provide well-resolved data at low velocities.

A possible explanation for this discrepancy is that the nature of the compression of the soap billet in the compressed slip device, in conjunction with the low velocity, enforces stronger wall-soap interaction than in the flowing systems. This is corroborated by the stronger pressure dependence result than in either flowing system. Stronger pressure dependence at low velocities in an alumina paste was hypothesised by Benbow and Bridgwater (1987) to be due to stickslip interaction, and that at higher velocities the paste did not have sufficient time to form strong adhesive bonds with the wall. 


\section{Conclusions}

The wall slip behaviour of a solid granular soap has been shown to be non-

370 tion of wall slip in extrusion flow both attempt to decouple the measurement of wall shear stresses from the bulk deformation behaviour, and in doing so allow greater control over the conditions of wall slip, namely the pressure of the material in contact with the wall. For the case of soap, there was found to be no

trivial and worthy of further study. The techniques developed for the investigainfluence of pressure on $\tau_{\mathrm{W}}$ at larger slip velocities in the range $0-50 \mathrm{~mm} / \mathrm{s}$, but some effect at low velocities and when sufficient confining pressure was applied using the compressed slip device. The two methods developed are complementary in terms of the slip velocities they can measure. However, further work is required to refine the protocols in order to reduce scatter in the experimental data.

Also investigated were the effects of the barrel and die material on the extrusion behaviour, focusing in particular on the wall slip behaviour of the soap. The sequence of experiments indicated that the wall shear stress against a cemented tungsten carbide wall was greater than that in a stainless steel extruder, and greater still than in a polycarbonate extruder. The slip behaviour was consistently found to be of a power-law in slip velocity-type, with a negligible slip yield stress $\left(\tau_{0}\right)$. The experiments were unable to control the surface roughnesses of the extrusion tooling, such that the trends must be interpreted in the context of both the material and the surface finish. The trend in the data does correspond to differences in the thermal diffusivity of the three materials, and also correlates with the roughness if it is assumed that frictional heating is significant. Further work is required to isolate the effects of wall material and surface roughness on the slip behaviour. The current findings nevertheless indicate a need to consider these factors when interpreting data gathered with different extruders or from the literature. 


\section{Acknowledgements}

Funding for this project was kindly provided by Ceratizit GmbH and Sandvik $\mathrm{AB}$.

\section{Nomenclature}

\section{Roman}

$b \quad$ Slip length $[\mathrm{m}]$

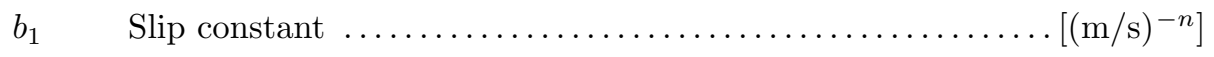

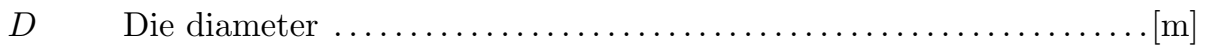

$D_{\mathrm{p}} \quad$ Primary die diameter $\ldots \ldots \ldots \ldots \ldots \ldots \ldots \ldots \ldots \ldots \ldots \ldots \ldots \ldots \ldots \ldots \ldots$

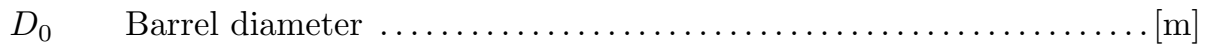

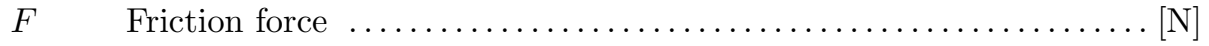

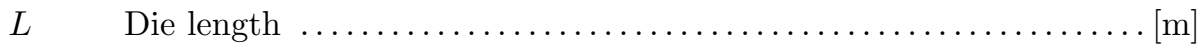

$L_{\mathrm{b}} \quad$ Billet length $\ldots \ldots \ldots \ldots \ldots \ldots \ldots \ldots \ldots \ldots \ldots \ldots \ldots \ldots \ldots \ldots \ldots \ldots \ldots \ldots \ldots$

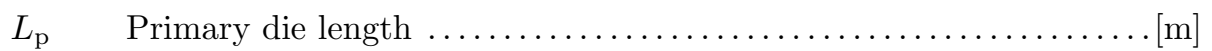

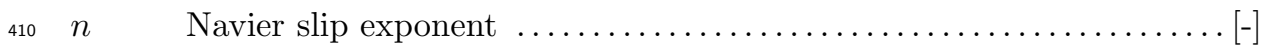

$P \quad$ General pressure $\ldots \ldots \ldots \ldots \ldots \ldots \ldots \ldots \ldots \ldots \ldots \ldots \ldots \ldots \ldots \ldots \ldots \ldots \ldots \ldots$

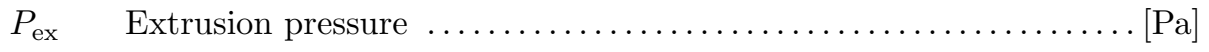

$r \quad$ Radial coordinate $\ldots \ldots \ldots \ldots \ldots \ldots \ldots \ldots \ldots \ldots \ldots \ldots \ldots \ldots \ldots \ldots \ldots \ldots$

$R_{\mathrm{a}} \quad$ Arithmetic average of absolute surface roughness $\ldots \ldots \ldots \ldots \ldots[\mathrm{m}]$

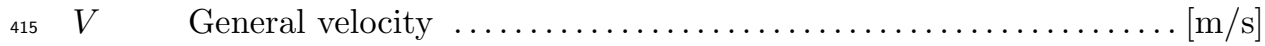

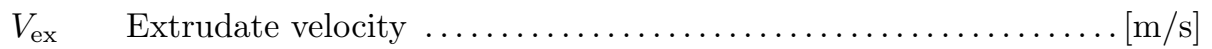

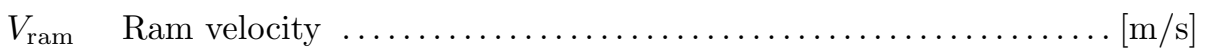




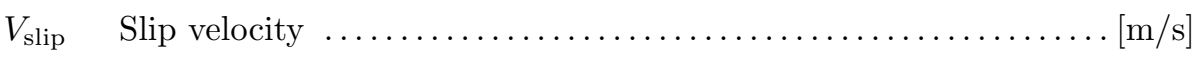

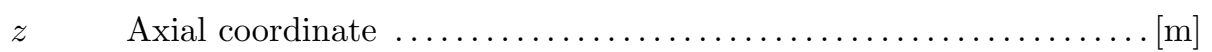

${ }_{420}$ Greek

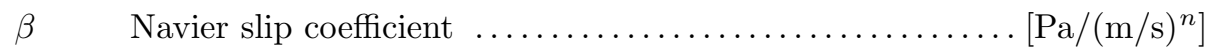

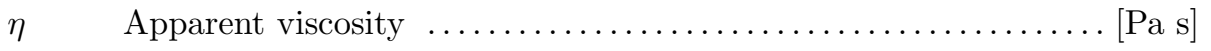

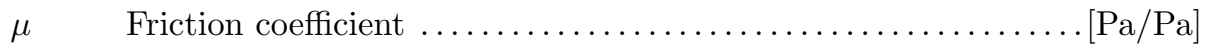

$\sigma_{\mathrm{Y}} \quad$ Benbow-Bridgwater yield stress $\ldots \ldots \ldots \ldots \ldots \ldots \ldots \ldots \ldots \ldots \ldots \ldots \ldots \ldots$

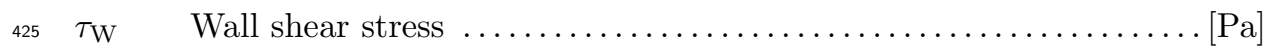

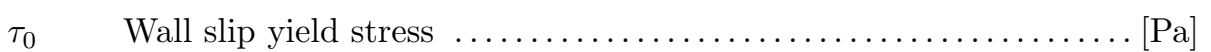

\section{Abbreviations}

PC Polycarbonate

SS Stainless steel

WC Tungsten carbide

\section{Bibliography}

Amarasinghe, S., Wilson, D. I. (1998). "Interpretation of paste extrusion data." Chemical Engineering Research and Design, 76(1), 1-6. doi:10.1205/026387698524523

Ansari, M., Hatzikiriakos, S. G., Mitsoulis, E. (2012). "Slip effects in HDPE flows." Journal of Non-Newtonian Fluid Mechanics, 167-168, 18-29. doi:10.1016/j.jnnfm.2011.09.007

Barnes, E. C., Wilson, D. I., Johns, M. L. (2006). "Velocity profiling inside a ram extruder using magnetic resonance (MR) techniques." Chemical Engineering Science, 61(5), 1357-1367. doi:10.1016/j.ces.2005.08.032 
Barnes, H. A. (1995). "A review of the slip (wall depletion) of polymer solutions, emulsions and particle suspensions in viscometers: its cause, character, and cure." Journal of Non-Newtonian Fluid Mechanics, 56(3), 221-251. doi:10.1016/0377-0257(94)01282-M

${ }_{445}$ Benbow, J. J., Bridgwater, J. (1987). "The role of frictional forces in paste extrusion." In Briscoe, B. J., Adams, M. J. (eds.), Tribology in Particulate Technology, p. 80. Adam Hilger. ISBN 0852744250

Benbow, J. J., Bridgwater, J. (1993). Paste Flow and Extrusion. Clarendon Press. ISBN 9780198563389

Blau, P. J., Bayer, R. G. (2003). Wear of materials. Elsevier. ISBN 9780080443010

Blumm, J., Lindemann, A., Niedrig, B., Campbell, R. (2007). "Measurement of selected thermophysical properties of the NPL certified reference material stainless steel 310." International Journal of Thermophysics, 28(2), 674-682. doi:10.1007/s10765-007-0177-z

Bryan, M., Rough, S., Wilson, D. (2017). "Flow visualisation and modelling of solid soap extrusion." Chemical Engineering Science, 173, 110 - 120. doi:10.1016/j.ces.2017.07.028

Bryan, M. P., Rough, S. L., Wilson, D. I. (2015). "Investigation of static zones and wall slip through sequential ram extrusion of contrasting micro-crystalline cellulose-based pastes." Journal of Non-Newtonian Fluid Mechanics, 220, 5768. doi:10.1016/j.jnnfm.2014.08.007

Choy, C. L., Leung, W. P., Ng, Y. K. (1987). "Thermal diffusivity of polymer films by the flash radiometry method." Journal of Polymer Science Part B: Polymer Physics, 25(9), 1779-1799. doi:10.1002/polb.1987.090250901

Domanti, A. T. J., Bridgwater, J. (2000). "Surface fracture in axisymmetric paste extrusion: An experimental study." Chemical Engineering Research and Design, 78(1), 68-78. doi:10.1205/026387600526898 
Hatzikiriakos, S. G., Dealy, J. M. (1992). "Wall slip of molten high density polyethylenes. II. Capillary rheometer studies." Journal of Rheology, 36(4), 703-741. doi:10.1122/1.550313

Hatzikiriakos, S. G., Mitsoulis, E. (2009). "Slip effects in tapered dies." Polymer Engineering ES Science, 49(10), 1960-1969. doi:10.1002/pen.21430

Jastrzebski, Z. D. (1967). "Entrance effects and wall effects in an extrusion rheometer during flow of concentrated suspensions." Industrial \& Engineering Chemistry Fundamentals, 6(3), 445-454. doi:10.1021/i160023a019

Kalyon, D. M. (2005). "Apparent slip and viscoplasticity of concentrated suspensions." Journal of Rheology, 49(3), 621-640. doi:10.1122/1.1879043

Kalyon, D. M., Gevgilili, H., Yazici, R., Post, A. J., McFann, G. J. (2004). "Flow and structure development behavior of bar soaps containing synthetic detergent." Rheologica Acta, 43(4), 396-405. doi:10.1007/s00397-004-0357-8

Krieger, I. M., Dougherty, T. J. (1959). "A mechanism for non-Newtonian flow in suspensions of rigid spheres." Transactions of the Society of Rheology, 3(1), 137-152. doi:10.1122/1.548848

Leighton, D., Acrivos, A. (1987). "The shear-induced migration of particles in concentrated suspensions." Journal of Fluid Mechanics, 181, 415-439. doi:10.1017/S0022112087002155

Martin, P. J., Wilson, D. I. (2005). "A critical assessment of the Jastrzebski interface condition for the capillary flow of pastes, foams and polymers." Chemical Engineering Science, 60(2), 493-502. doi:10.1016/j.ces.2004.08.011

Mitsoulis, E., Hatzikiriakos, S. G. (2009). "Steady flow simulations of compressible PTFE paste extrusion under severe wall slip." Journal of Non-Newtonian Fluid Mechanics, 157(1-2), 26-33. doi:10.1016/j.jnnfm.2008.09.003

Mooney, M. (1931). "Explicit formulas for slip and fluidity." Journal of Rheol495 ogy, 2(2), 210-222. doi:10.1122/1.2116364 
Navier, C. L. M. H. (1823). "Mémoire sur les lois du mouvement des fluids." Mem. Acad. Sci. Inst. Fr., 6, 432-436

Stewart, C. W. (1993). "Wall slip in the extrusion of linear polyolefins." Journal of Rheology, 37(3), 499-513. doi:10.1122/1.550456

${ }_{500}$ Tang, H. S., Kalyon, D. M. (2008). "Time-dependent tube flow of compressible suspensions subject to pressure dependent wall slip: Ramifications on development of flow instabilities." Journal of Rheology, 52(5), 1069-1090. doi:10.1122/1.2955508

Wang, Z. Y., Lam, Y. C., Chen, X., Joshi, S. C. (2010). "Viscosity corrections for concentrated suspension in capillary flow with wall slip." American Institute of Chemical Engineers Journal, 56(6), 1447-1455. doi:10.1002/aic.12095

Wilson, D. I., Rough, S. L. (2006). "Exploiting the curious characteristics of dense solid-liquid pastes." Chemical Engineering Science, 61(13), 4147-4154. doi:10.1016/j.ces.2005.10.032

Yoshimura, A., Prud'Homme, R. K. (1988). "Wall slip corrections for Couette and parallel disk viscometers." Journal of Rheology, 32(1), 53-67. doi:10.1122/1.549963 


\section{List of Figures}

1 Schematic diagram of the vertical, concentric cylinder ram ex-

515 truder with a square-entry geometry used for the standard extrusion experiments. The barrel diameter $(25 \mathrm{~mm})$ corresponds to $D_{0}$, while $3 \mathrm{~mm}$ is the die diameter, $D . \ldots \ldots \ldots . \ldots 24$

2 Diagram of the two-stage extrusion die in cross-section. . . . . . 25

3 (a) Image of the compressed slip device outside of the cylindrical channel. (b) Cross-section diagram of the compressed slip device located inside the cylindrical channel. . . . . . . . . . . 26

4 Effect of material of extruder construction on the Benbow-Bridgwater parameters $\tau_{\mathrm{W}}$ and $\sigma_{\mathrm{Y}}$ for soap, from the apparatus described in figure 1. Each data point is obtained from a straight line fit to twelve extrusion experiments with six dies (each repeated twice). Bars indicate $90 \%$ confidence intervals to the straight line fits. Barrels of diameter $25 \mathrm{~mm}$ and dies of diameter $3 \mathrm{~mm}$. . . . . . 27

5 Extrusion profiles of soap through the two-stage extrusion die using a secondary die of length $22 \mathrm{~mm}$ and diameter $3 \mathrm{~mm}$. (a) $V_{\text {slip }}=1.25 \mathrm{~mm} / \mathrm{s}$ and (b) $V_{\text {slip }}=40 \mathrm{~mm} / \mathrm{s} \ldots \ldots 28$

$6 \tau_{\mathrm{W}}$ for soap as a function of ram displacement for each of four secondary dies, three with diameter $3 \mathrm{~mm}$ and lengths 5,22 and $35 \mathrm{~mm}$, and one with diameter $4 \mathrm{~mm}$ and length $5 \mathrm{~mm}$, at $V_{\text {slip }}=30 \mathrm{~mm} / \mathrm{s}$ in the primary die. The mean of each trace, used in further analysis, was taken over the width marked by the horizontal lines. . . . . . . . . . . . . . . . .

7 Wall shear stress derived from two-stage die extrusions with soap as a function of (a) pressure in the primary die, and (b) slip velocity in the primary die. Lines represent a least-squares linear fit to the data shown on each plot, and do not account for any effect of coupled pressure and velocity dependence. . . . . . . . 30

8 Slip force profile for soap using the compressed slip device, increasing the slip velocity after each upward/downward cycle, finishing on a repeat of the lowest slip velocity. Confining pressure on the order of $5 \mathrm{MPa}$ and billet length $19 \mathrm{~mm}$. Slip velocity varies from $0.5 \mathrm{~mm} / \mathrm{s}$ (repeated), then $1-7 \mathrm{~mm} / \mathrm{s}$ in $1 \mathrm{~mm} / \mathrm{s}$ increments. . . . . . . . . . . . . . . . . .

9 Wall shear stress measured using the compressed slip device for soap billets of different aspect ratios $\left(L_{\mathrm{b}} / D_{0}\right)$ at a confining pressure of $20 \mathrm{MPa} \pm 2 \mathrm{MPa} . D_{0}=25 \mathrm{~mm} . \ldots \ldots \ldots . \ldots . \ldots 32$

10 Wall shear stress measured using the compressed slip device for soap billets of length $19 \mathrm{~mm}\left(L_{\mathrm{b}} / D_{0}=0.76\right)$ as a function of (a) slip velocity and (b) confining pressure. . . . . . . . . . 33 
11 Comparison of wall shear stress values from all three methods presented over the intermediate velocity range of $0-50 \mathrm{~mm} / \mathrm{s}$. The line for the SS extruder is the same as shown in figure 4(a) (data points omitted for clarity), while the lines for the two-stage extrusion die and compressed slip device were generated using the models fitted to the experimental data for each device (equation 4 ), evaluated at $10 \mathrm{MPa}$ where appropriate (representative of the pressure in the stainless steel extruder). . . . . . . . . . . 34 


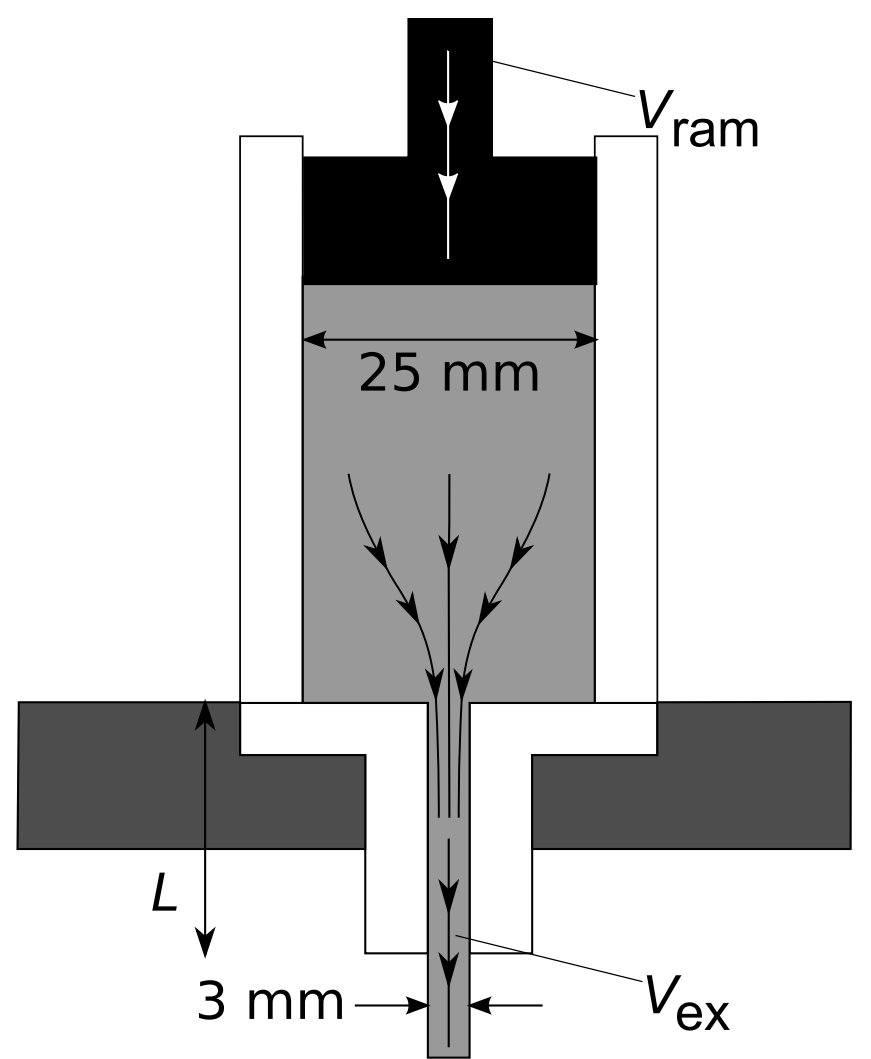

Figure 1: Schematic diagram of the vertical, concentric cylinder ram extruder with a squareentry geometry used for the standard extrusion experiments. The barrel diameter $(25 \mathrm{~mm})$ corresponds to $D_{0}$, while $3 \mathrm{~mm}$ is the die diameter, $D$. 


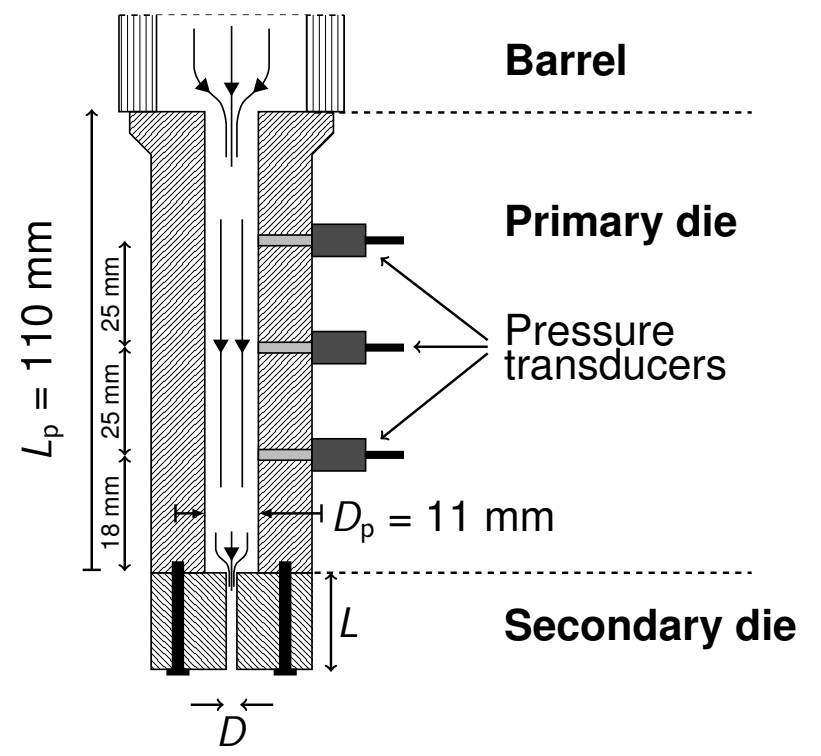

Figure 2: Diagram of the two-stage extrusion die in cross-section. 


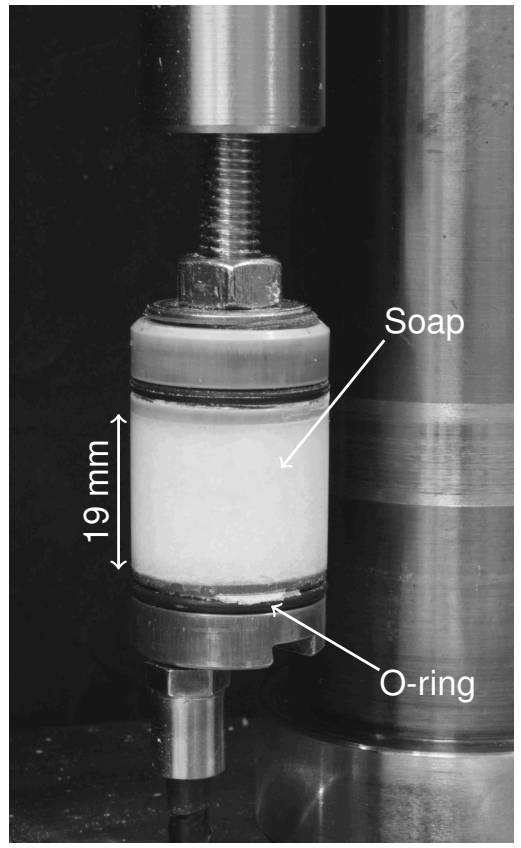

(a)

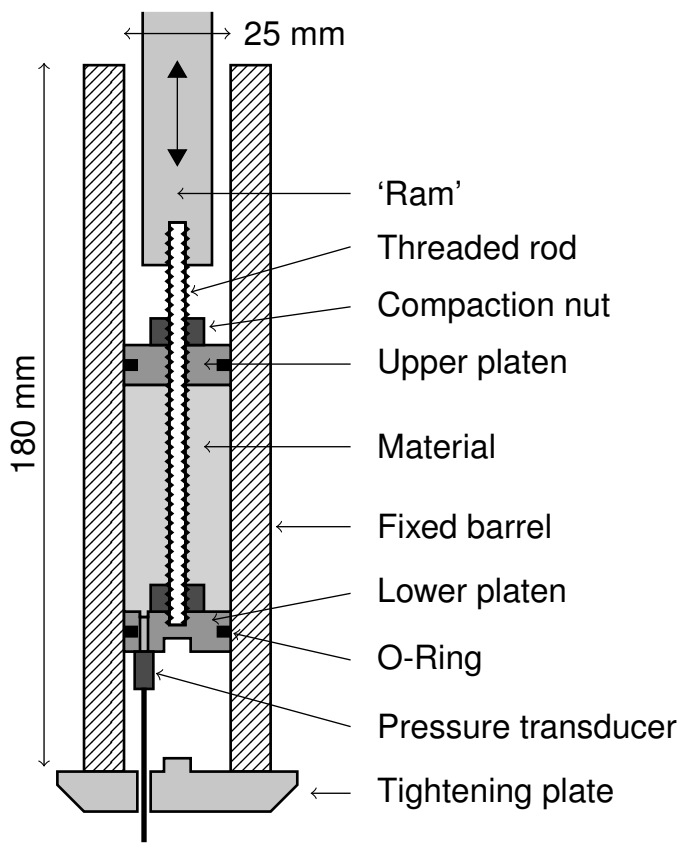

(b)

Figure 3: (a) Image of the compressed slip device outside of the cylindrical channel. (b) Cross-section diagram of the compressed slip device located inside the cylindrical channel. 


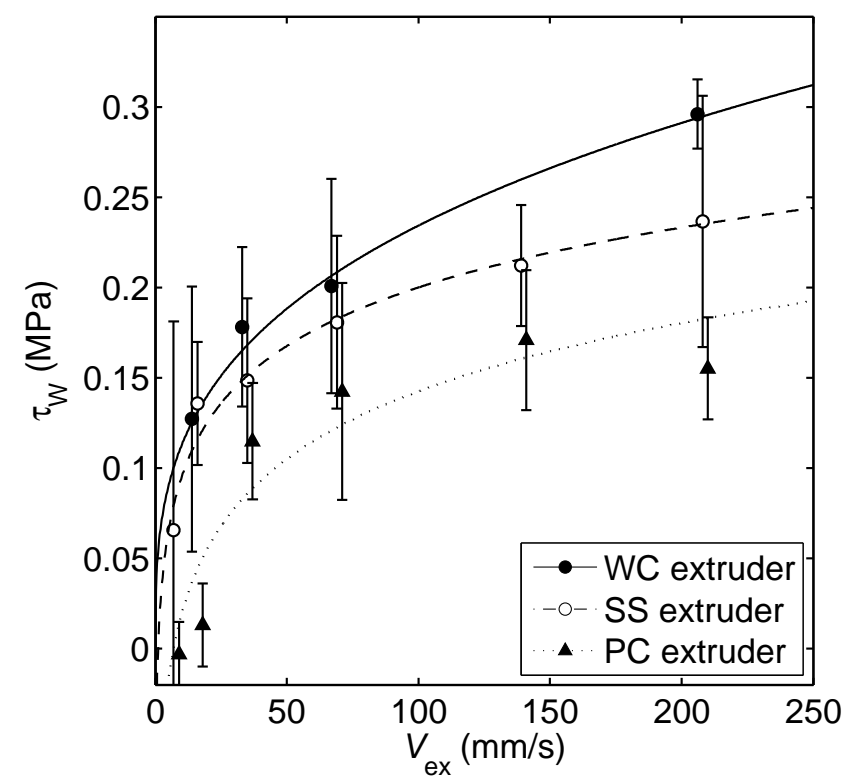

(a)

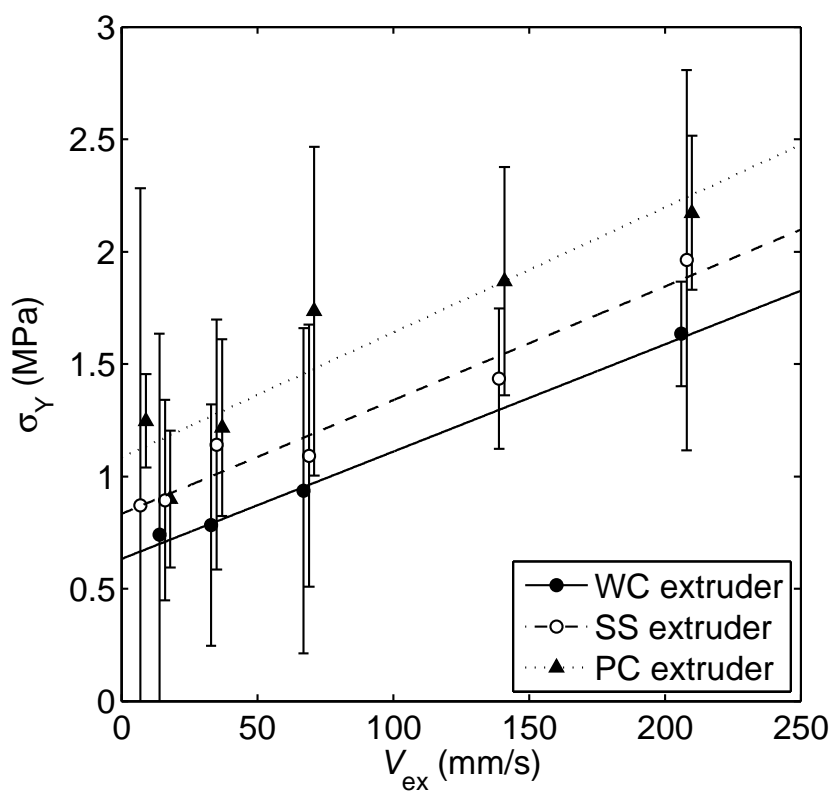

(b)

Figure 4: Effect of material of extruder construction on the Benbow-Bridgwater parameters $\tau_{\mathrm{W}}$ and $\sigma_{\mathrm{Y}}$ for soap, from the apparatus described in figure 1. Each data point is obtained from a straight line fit to twelve extrusion experiments with six dies (each repeated twice). Bars indicate $90 \%$ confidence intervals to the straight line fits. Barrels of diameter $25 \mathrm{~mm}$ and dies of diameter $3 \mathrm{~mm}$. 


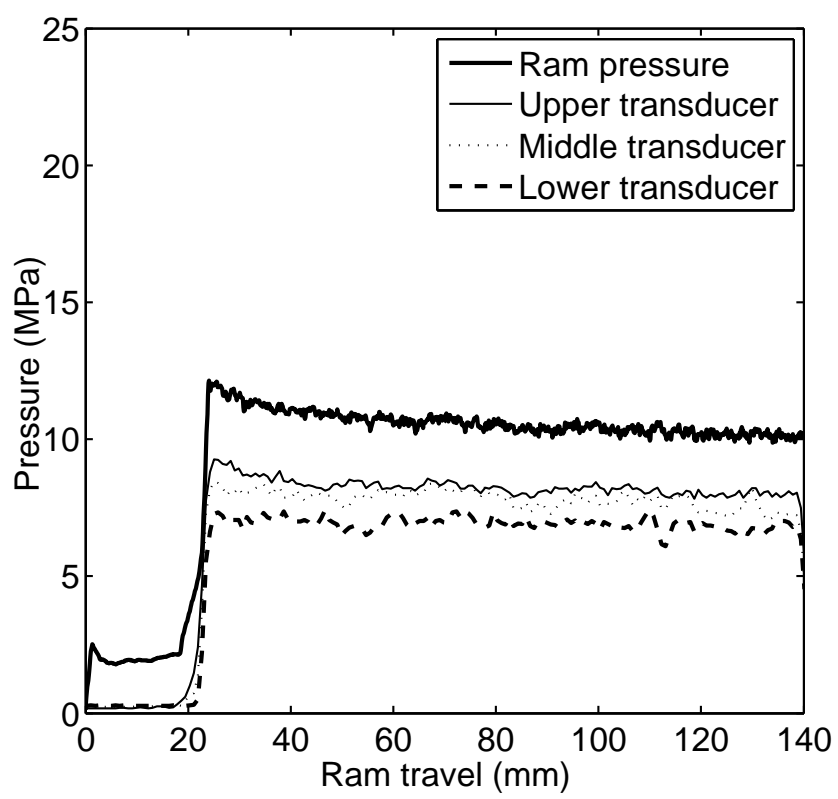

(a)

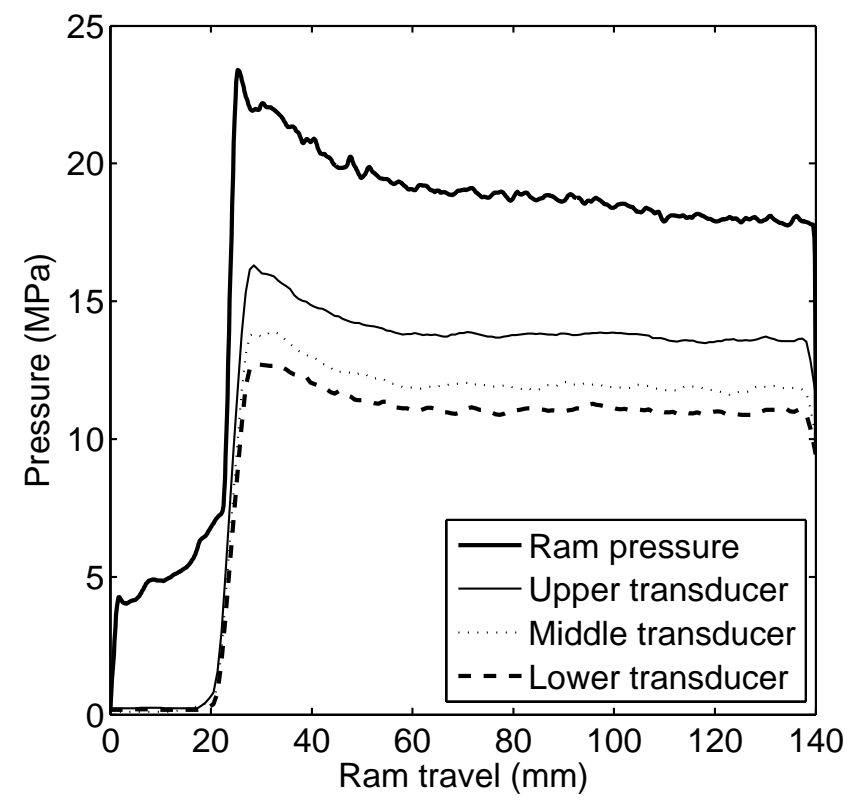

(b)

Figure 5: Extrusion profiles of soap through the two-stage extrusion die using a secondary die of length $22 \mathrm{~mm}$ and diameter $3 \mathrm{~mm}$. (a) $V_{\text {slip }}=1.25 \mathrm{~mm} / \mathrm{s}$ and (b) $V_{\text {slip }}=40 \mathrm{~mm} / \mathrm{s}$ 


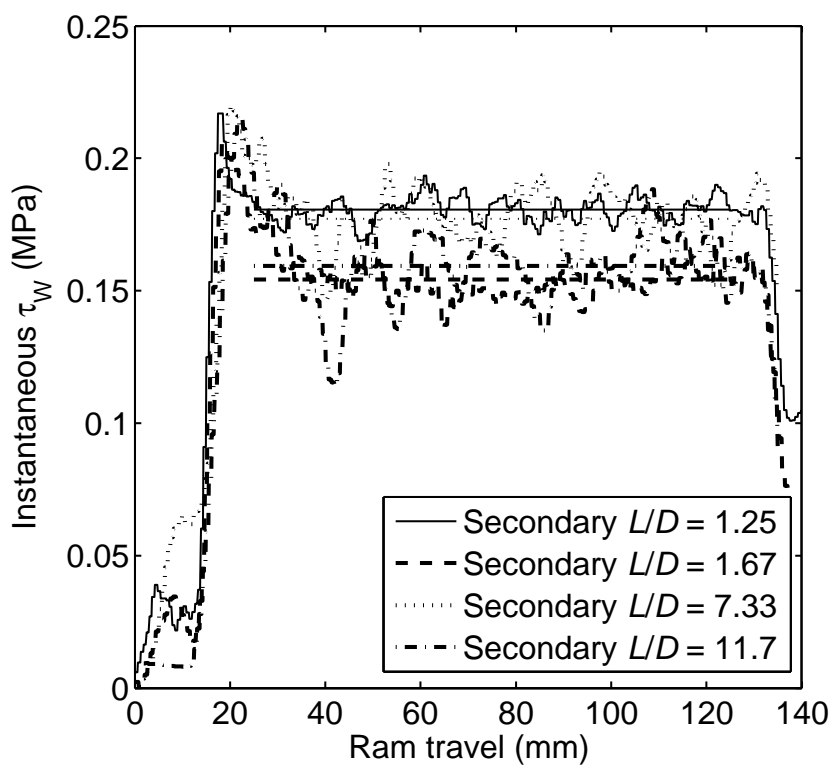

Figure 6: $\tau_{\mathrm{W}}$ for soap as a function of ram displacement for each of four secondary dies, three with diameter $3 \mathrm{~mm}$ and lengths 5,22 and $35 \mathrm{~mm}$, and one with diameter $4 \mathrm{~mm}$ and length $5 \mathrm{~mm}$, at $V_{\text {slip }}=30 \mathrm{~mm} / \mathrm{s}$ in the primary die. The mean of each trace, used in further analysis, was taken over the width marked by the horizontal lines. 


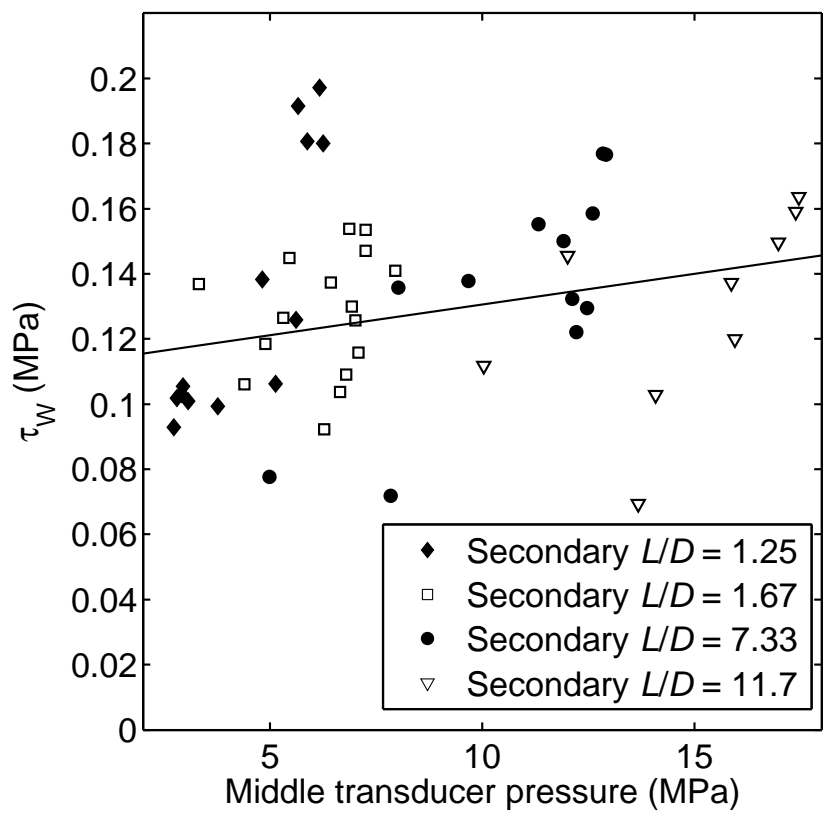

(a)

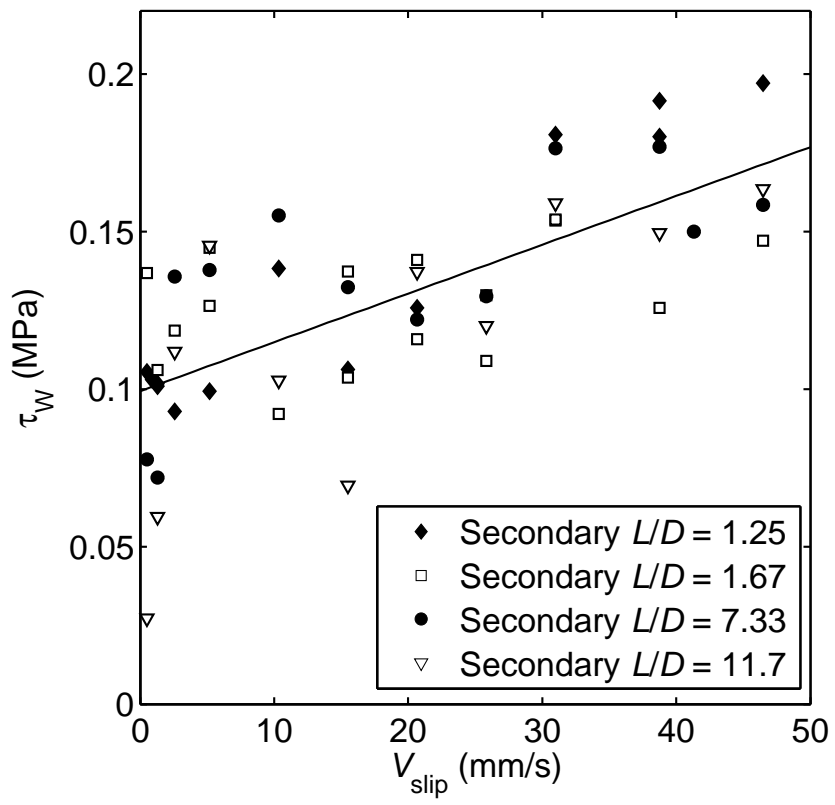

(b)

Figure 7: Wall shear stress derived from two-stage die extrusions with soap as a function of (a) pressure in the primary die, and (b) slip velocity in the primary die. Lines represent a least-squares linear fit to the data shown on each plot, and do not account for any effect of coupled pressure and velocity dependence. 


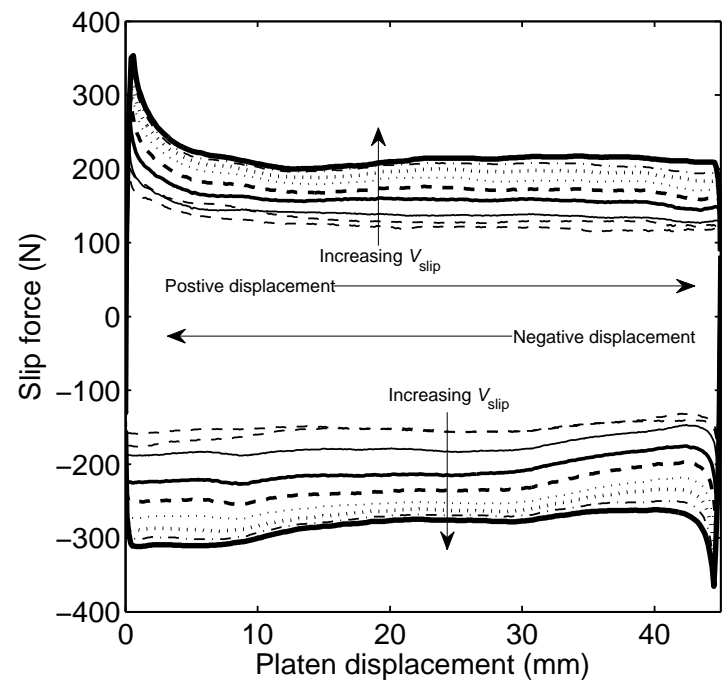

Figure 8: Slip force profile for soap using the compressed slip device, increasing the slip velocity after each upward/downward cycle, finishing on a repeat of the lowest slip velocity. Confining pressure on the order of $5 \mathrm{MPa}$ and billet length $19 \mathrm{~mm}$. Slip velocity varies from $0.5 \mathrm{~mm} / \mathrm{s}$ (repeated), then $1-7 \mathrm{~mm} / \mathrm{s}$ in $1 \mathrm{~mm} / \mathrm{s}$ increments. 


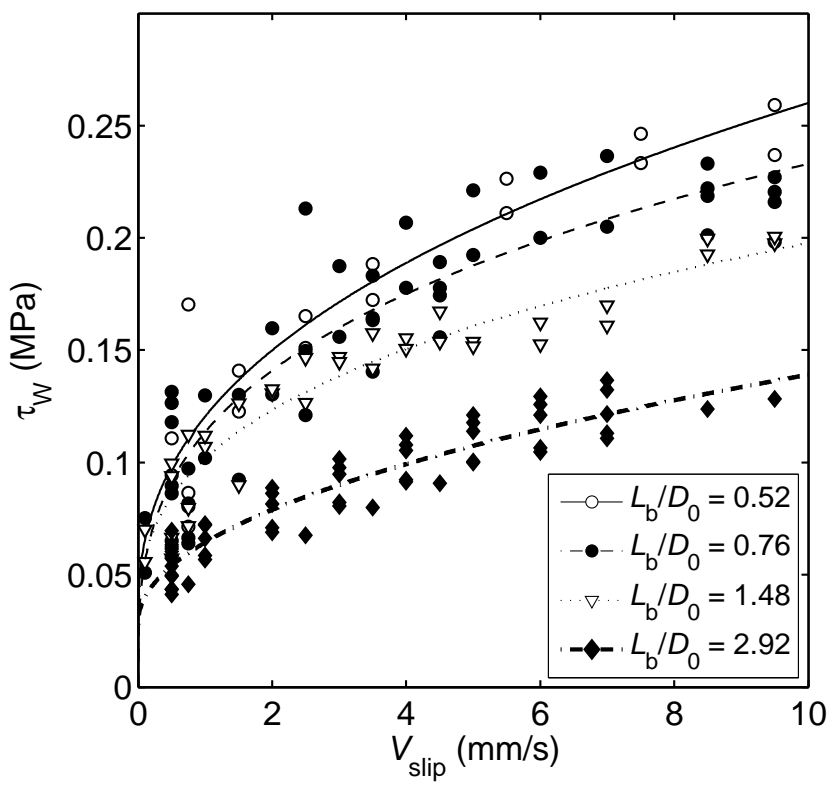

Figure 9: Wall shear stress measured using the compressed slip device for soap billets of different aspect ratios $\left(L_{\mathrm{b}} / D_{0}\right)$ at a confining pressure of $20 \mathrm{MPa} \pm 2 \mathrm{MPa}$. $D_{0}=25 \mathrm{~mm}$. 


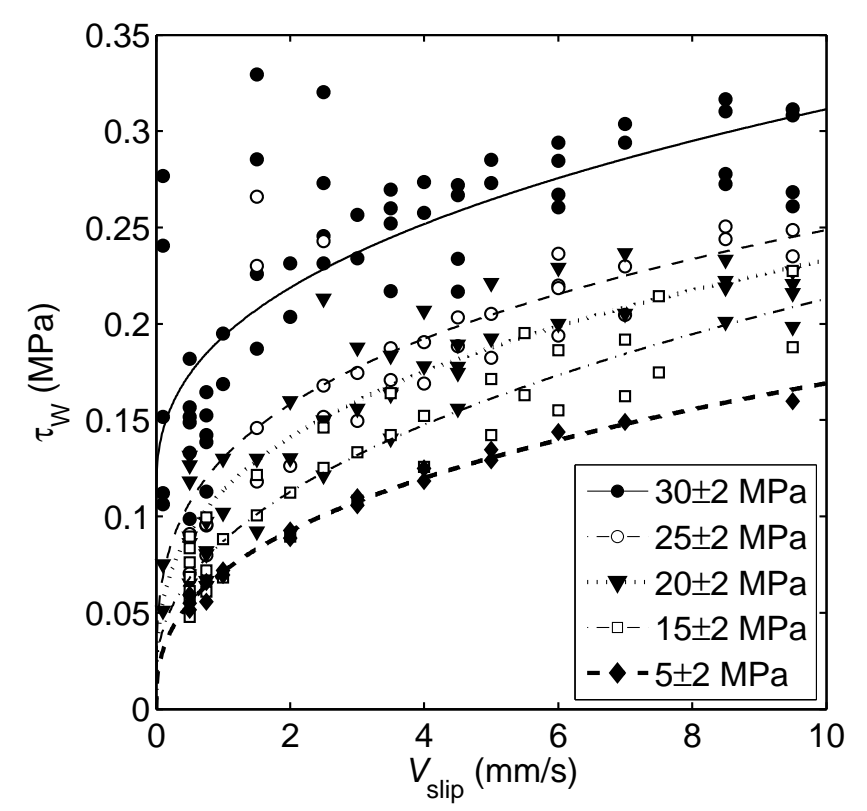

(a)

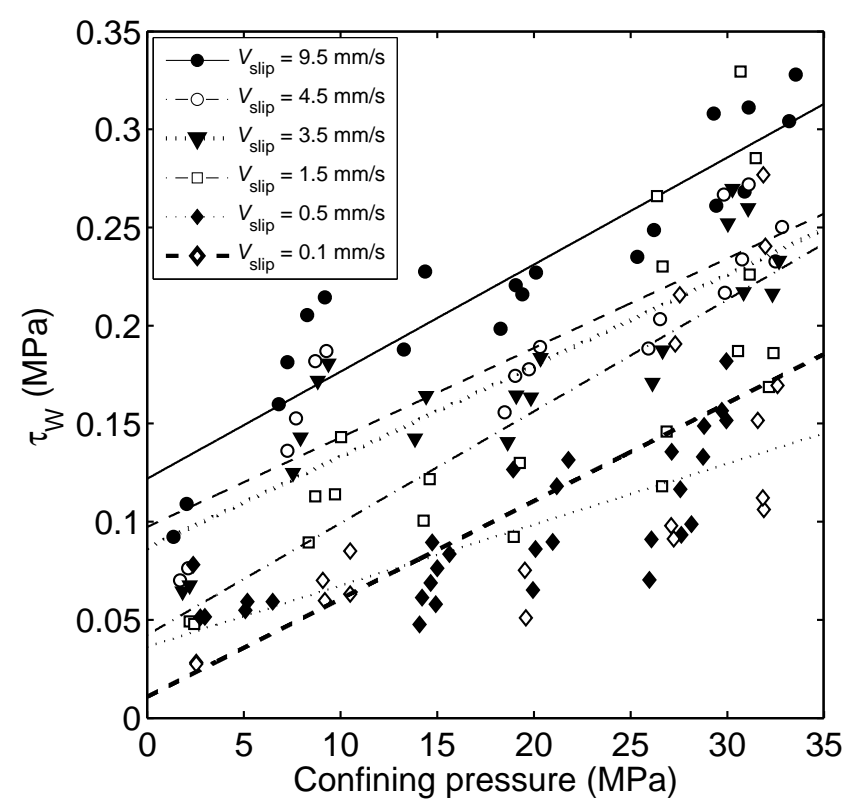

(b)

Figure 10: Wall shear stress measured using the compressed slip device for soap billets of length $19 \mathrm{~mm}\left(L_{\mathrm{b}} / D_{0}=0.76\right)$ as a function of (a) slip velocity and (b) confining pressure. 


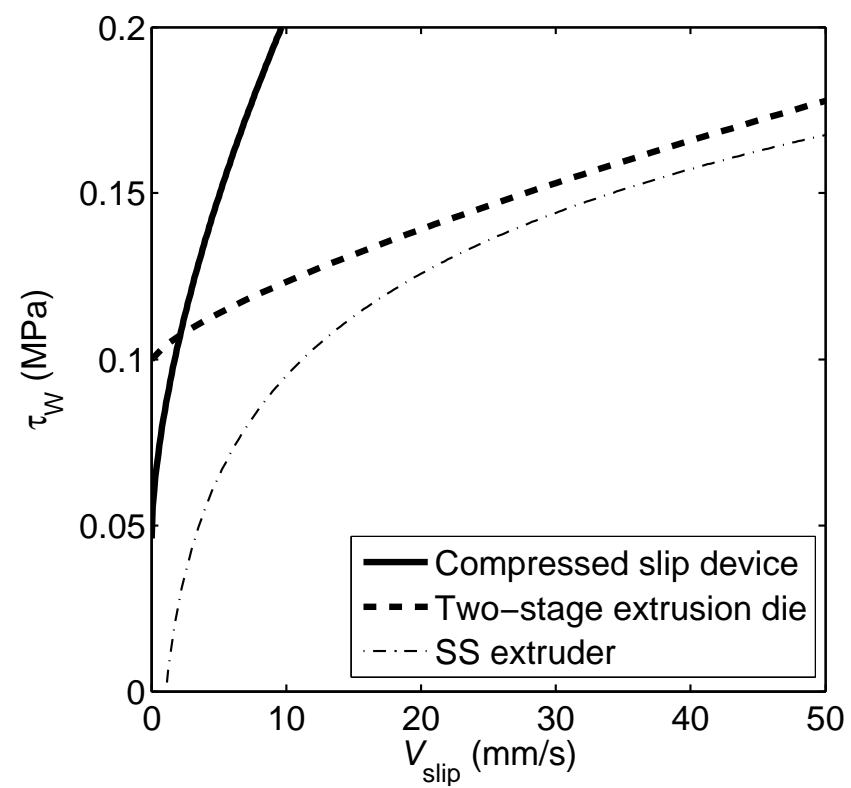

Figure 11: Comparison of wall shear stress values from all three methods presented over the intermediate velocity range of $0-50 \mathrm{~mm} / \mathrm{s}$. The line for the SS extruder is the same as shown in figure 4(a) (data points omitted for clarity), while the lines for the two-stage extrusion die and compressed slip device were generated using the models fitted to the experimental data for each device (equation 4), evaluated at $10 \mathrm{MPa}$ where appropriate (representative of the pressure in the stainless steel extruder). 


\section{List of Tables}

1 Data on the three extruders used. Surface roughness measurements are of the barrel walls taken using stylus profilometry. . . 36 
Table 1: Data on the three extruders used. Surface roughness measurements are of the barrel walls taken using stylus profilometry.

\begin{tabular}{lrrl}
\hline Material & Wall roughness $R_{\mathrm{a}}(\mu \mathrm{m})$ & Thermal diffusivity $\left(\mathrm{m}^{2} / \mathrm{s}\right)$ & Reference \\
\hline Tungsten carbide (WC) & 0.039 & $1.0 \times 10^{-5}$ & Blau and Bayer (2003) \\
Stainless steel (SS) & 0.102 & $3.5 \times 10^{-6}$ & Blumm et al. (2007) \\
Polycarbonate (PC) & 1.940 & $1.4 \times 10^{-7}$ & Choy et al. (1987) \\
\hline
\end{tabular}

